\title{
Landscape functional connectivity for butterflies under different scenarios of land-use, land-cover, and climate change in Australia
}

Vishesh L. Diengdoh ${ }^{1}$, e: vishesh.diengdoh@utas.edu.au, ORCID: https://orcid.org/0000$\underline{0002-0797-9261}$

Stefania Ondei ${ }^{1}$ - e: $\underline{\text { stefania.ondei@utas.edu.au }}$

Rahil J. Amin ${ }^{1}$ - e: RahilJasminkumar.Amin@utas.edu.au

Mark Hunt ${ }^{1,3}$ - e: M.Hunt@utas.edu.au

Barry W. Brook ${ }^{1,2}$ - e: barry.brook@utas.edu.au

${ }^{1}$ School of Natural Sciences, University of Tasmania, Private Bag 55, Hobart TAS 7005

Australia

${ }^{2}$ ARC Centre of Excellence for Australian Biodiversity and Heritage, Australia

${ }^{3}$ ARC Industrial Transformation Training Centre for Forest Value, Australia

Corresponding Author: Vishesh L. Diengdoh

\section{Authors contribution}

Conceptualisation: VLD; Methodology: VLD, BWB, SO, RJA; Analysis: VLD, RJA;

Writing (original draft): VLD; Writing (review) VLD, BWB, SO, RJA, MH; Supervision:

BWB, SO, MH; Funding: BWB.

\section{Declaration of competing interest}

None.

\section{Acknowledgements}

This work was supported by the Australian Research Council [grant number FL160100101]. 
bioRxiv preprint doi: https://doi.org/10.1101/2022.02.07.479372; this version posted February 10, 2022. The copyright holder for this preprint

(which was not certified by peer review) is the author/funder, who has granted bioRxiv a license to display the preprint in perpetuity. It is made available under aCC-BY-NC-ND 4.0 International license.

\section{Research Data}

The habitat suitability maps and functional connectivity maps are made available as GeoTiff images via Figshare (10.6084/m9.figshare.19130078). 


\section{Abstract}

2 Pollinating invertebrates are vital to terrestrial ecosystems but are impacted by anthropogenic

3 habitat loss/fragmentation and climate change. Conserving and improving landscape

4 connectivity is important to offset those threats, yet its assessment for invertebrates is

5 lacking. In this study, we evaluated the functional connectivity between protected areas in

6 Australia for 59 butterfly species, under present conditions and different future scenarios (for

72050 and 2090) of land-use, land-cover, and climate change. Using circuit-theory analysis,

8 we found that functional connectivity under present conditions varies widely between

9 species, even when their estimated geographical ranges are similar. Under future scenarios,

10 functional connectivity is predicted to decrease overall, with negative changes worsening

11 from 2050 to 2090 , although a few species are positive exceptions. We have made our results

12 available as spatial datasets to allow comparisons with taxa from other studies and can be

13 used to identify priority areas for conservation in terms of establishing ecological corridors or

14 stepping-stone habitat patches. Our study highlights the importance of considering pollinating

15 invertebrates when seeking holistic conservation and restoration of a landscape's functional

16 connectivity, underscoring the need to expand and promote protected areas to facilitate

17 functional connectivity under future scenarios of global change.

\section{Keywords}

19 Circuit theory, ecological corridors, habitat suitable models, Lepidoptera 


\section{Introduction}

21 Landscape connectivity is defined as the extent to which the landscape facilitates the

22 movement of organisms between habitat patches. It can be structural or functional; the former

23 is dependent on only the landscape structure, while the latter (which is of focus in this study)

24 also considers species attributes such as habitat preference and dispersal ability (Rudnick et

25 al. 2012; Costanza and Terando 2019). Habitat loss and fragmentation increase barriers

26 between suitable habitats reducing gene flow and the ability of a species to track climate

27 change. Maintaining and restoring landscape connectivity is considered as an important

28 adaptation strategy to reduce the impact of habitat loss and fragmentation and climate change

29 and thereby better conserve biodiversity (Rudnick et al. 2012; Costanza and Terando 2019;

$30 \quad$ Littlefield et al. 2019).

31 Studies on habitat connectivity (i.e., the degree of functional connectivity between patches of

32 preferred or obligate habitat for individual species) are typically biased towards mammals

33 and birds (Correa Ayram et al. 2016; Dickson et al. 2019). This leaves a gap in the literature

34 for invertebrates - particularly pollinating invertebrates-although there are exceptions (e.g.

35 Filz et al. 2013; Chen 2017; Kirk et al. 2018; Miranda et al. 2021). This gap needs to be

36 filled, as habitat connectivity is important for sustaining pollinator abundance, diversity, and

37 dispersal (Potts et al. 2016). Indeed preserving habitat connectivity is an important strategy

38 for conserving insects (Samways et al. 2020) and its loss can have a negative impact on

39 pollination (Mitchell et al. 2013).

40 Butterflies make for an ideal functional-connectivity case study because they are a major

41 pollinating taxon thought to be able to transfer pollen over larger distances than other insects

42 (Winfree et al. 2011) and are demonstrably impacted by habitat loss/fragmentation and

43 climate change (Miao et al. 2020; Warren et al. 2021). In some regions, available protected 
44 areas are inadequate for butterfly conservation (Chowdhury et al. 2021a) while in other cases,

45 the effectiveness of protected areas for butterflies is predicted to decrease under climate

46 change (Cheng and Bonebrake 2017). Expanding and improving the connectivity of protected

47 areas is part of the Aichi Biodiversity Targets (Target 11; Convention on Biological Diversity

48 2022). Thus, maintaining and promoting ecological corridors or stepping-stone habitats is

49 critical to facilitate species movement between metapopulations to prevent inbreeding and

50 promote recolonisation after extirpation events (Sands 2018), as well as to facilitate

51 movement in response to climate change (Stewart et al. 2019; Malakoutikhah et al. 2020).

52 The aim of this study is to assess the landscape-scale functional connectivity for butterflies

53 between protected areas in Australia, under both present conditions and different future

54 scenarios of land-use, land-cover and climate change (for 2050 and 2090). We assessed the

55 connectivity for 59 species of butterflies using the Circuitscape Julia package (Anantharaman

56 et al. 2020) which is based on circuit theory (McRae et al. 2008). Circuitscape uses circuit

57 theory to predict patterns of movement or dispersal of organisms or genes (McRae et al.

58 2008) and has been used for studying landscape population genetics and identifying animal

59 movement corridors (Dickson et al. 2019). Circuit theory operates on a continuous layer and

60 considers multiple pathways for movements, making it more flexible than other, simpler

61 methods like the least-cost pathway (McRae et al. 2008). We then considered the

62 conservation implications of our findings for habitat prioritisation.

\section{2. Materials and Methods}


66 Occurrence (presence) data were from the Atlas of Living Australia occurrence downloaded

67 at https://doi.org/10.26197/ala.9028e7dc-2566-44de-8999-dbb36c6685a9 Accessed 15

68 February 2021. Records were limited to those from 1960 onwards and classified as 'human

69 observation'. Duplicate records based on latitude and longitude were removed. We used

70 spatial thinning to reduce spatial autocorrelation by removing records closer than a minimum

71 nearest neighbour distance (NMD) using the R package spThin (Aiello-Lammens et al. 2015).

72 We followed the method by Amin et al. (2021) to find the optimal NMD for each species

73 separately - adjusting it based on the human activity index. To achieve this, firstly, we

74 stratified Australia into low, medium and high human activity grids of resolution $25 \mathrm{~km}^{2}$

75 using Global Human-Footprint data (Venter et al. 2018). Secondly, we removed all records

76 (i.e., of all species combined) closer than $1.25 \mathrm{~km}$ to ensure that data in low-density grids

77 were relatively uncorrelated. Then, for each species, we estimate the threshold number of re-

78 samples to be retained per grid $(h)$ using: $\mathrm{h}=\mathrm{n}_{\mathrm{i}} / \mathrm{N}_{\mathrm{i}}$ where $n_{\mathrm{i}}$ represents the number of samples

79 in low-activity grids and $N i$ is the number of low-activity grids. The threshold values were

80 then applied to calculate the maximum number of re-samples to be retained from medium and

81 high-density grids, using the formula: $\mathrm{n}_{\mathrm{jk}}=\mathrm{h} \times \mathrm{N}_{\mathrm{jk}}$, where $n$ is the maximum number of re-

82 samples from medium $j$ or high $k$ density grids, and $N$ is the number of medium $j$ or high

83 grids $k$. This was repeated 20 times per sampling run and tuned the NMD for high- and

84 medium-activity grids to achieve the maximum number of re-samples $\left(\mathrm{n}_{j k}\right)$ for each species.

85 To enable robust model training and validation, we selected only species with at least 100

86 unique occurrence records (after removing duplicates and accounting for spatial

87 autocorrelation) for high model performance and estimation of geographical ranges. An

88 exception to this rule was made for the Ptunarra Brown Butterfly (Oreixencia ptunarra

89 Couchman 1953) which had 96 records as it is a threatened species (Geyle et al. 2021). We

90 pooled all subspecies into their respective species as this enabled each species to have an 
91 adequate number of occurrence records. Consequently, we modelled 59 species in this study,

92 belonging to the Nymphalidae, Lycaenidae, Hesperiidae, Papilionidae families (Supplemental

93 Table A1).

942.2 Habitat suitability models

95 In this study, we used habitat-suitability maps as the 'resistance layer' which represents the

96 degree to which the landscape facilitates or blocks the movement of an individual across a

97 given cell. Here, high suitability indicates low resistance (and therefore, a high probability of

98 movement). Habitat suitability models are commonly used to estimate resistance in

99 connectivity models (Correa Ayram et al. 2016), and this approach has the advantage of also

100 providing an opportunity to assess the potential impact of climate change on functional

101 connectivity (Ashrafzadeh et al. 2019; Bonnin et al. 2020; Malakoutikhah et al. 2020).

102 To model habitat suitability, we selected all 19 bioclimatic variables (version 2.1;

103 https://www.worldclim.org; Fick and Hijmans 2017), elevation (https://www.worldclim.org),

104 and land-use and land-cover change (LULCC; Li et al. 2017) as predictors. The LULCC

105 variable was resampled to match the resolution of the bioclimatic and elevation variables

$106\left(0.05^{\circ}\right.$, or $\sim 5 \mathrm{~km}$ at Australian latitudes) using the raster $\mathrm{R}$ package (Hijmans 2020$)$. We then

107 reduced the number of predictors by removing highly correlated predictors using a threshold

108 value of 0.7 (Dormann et al. 2013) and implemented using the findCorrelation function in

109 caret $\mathrm{R}$ package (Kuhn 2021). If two variables were highly correlated, then the variable with

110 the largest mean absolute correlation was removed. All non-correlated predictors were used

111 for model fitting for each species (Supplementary Table A1).

112 The study area for each species was constrained using its estimated kernel geographical

113 range, which was implemented using the adehabitatHR $\mathrm{R}$ package (Calenge 2006). We

114 assumed that a species can disperse within the entirety of its geographical range. 
115 Pseudo-absences were generated using a random sampling method, with the presence to

116 pseudo-absence ratio set to unity. We used k-fold cross-validation $(k=10)$ for algorithm

117 optimisation and implemented using the caret $\mathrm{R}$ package (Kuhn 2021). The algorithms used

118 in the study include random forest, artificial neural network, k-nearest neighbour, flexible

119 discriminant analysis, and naïve Bayes, as they have different operating mechanisms and so

120 capture a diversity of machine-learning approaches.

121 Random forest is decisions trees based on bagging (Breiman 2001). Artificial neural network

122 consists of a network of neurons that are considered as the processing units in a strictly feed-

123 forward neural network (Sazli 2006). k-nearest neighbour works under the assumption that

124 similar things exist in proximity (in parameter hyperspace) and thus classifies data most

125 common among its neighbours (Cover and Hart 1967). Flexible discriminant analysis uses

126 multivariate adaptive regression splines to separate the data (Hastie et al. 1994), while naïve

127 Bayes is based on conditional probability (Ren et al. 2009).

128 Habitat-suitability models were fitted using the trained algorithms, and then ensembled. An

129 ensemble algorithm averages the prediction of structurally different algorithms and has the

130 potential to overcome uncertainty in model selection and improve prediction accuracy by

131 reducing variance and bias (Dormann et al. 2018). As such, we averaged the algorithms using

132 an unweighted method and assessed the goodness of fit using AUC and TSS (Allouche et al.

133 2006).

134 To account for the influence of global climate models (GCMs) we selected CanESM5 and

135 MIROC6, which have been used in previous studies in Australia (e.g., Briscoe et al. 2016;

136 Ofori et al. 2017; Morán $\square$ Ordóñez et al. 2018) under Shared Socio-economic Pathways

137 (SSP) 7.0, a high-emission scenario (IPCC 2021). For the LULCC variable, we selected A1

138 (low population growth, sprawling urban expansion, very high economic growth, rapid 
139 technological innovation, strong biofuels demand including cellulose-based ethanol) and B1

140 (low population growth, compact urban expansion, high economic growth, medium

141 technological innovation, low overall energy use, lower demand for biofuels) scenarios which

142 are both oriented globally ( $\mathrm{Li}$ et al. 2017). Future predictions were made for each species per

143 algorithm per year per climate model per LULCC scenario, and then ensembled (unweighted)

144 per year (2050 and 2090).

\subsection{Functional connectivity models}

146 Functional connectivity was assessed using the Circuitscape package in the Julia

147 Programming Language (Anantharaman et al. 2020). Circuitscape calculates connectivity

148 between focal nodes (habitat patches or populations) across a resistance layer (represents the

149 degree to which the landscape impedes the movement of an individual across a given cell)

150 and in analogy to an integrated circuit board in electronics, then calculates the effective

151 resistance and 'current flow' which in the ecological interpretation is a measure of net

152 movement probability (McRae et al. 2008). The modelling of functional connectivity results

153 in maps with cumulative current, where the intensity of current is a proxy for a species'

154 movement at each pixel (Grafius et al. 2017).

155 In this study, we used the centroids of protected areas as focal nodes (Mukherjee et al. 2021);

156 for this purpose, we only selected protected areas with an average habitat suitability of $\geq 0.7$

157 as this represented a high threshold of suitability. We identified focal nodes for each species

158 individually, under present climate conditions and future climate-change scenarios (for 2050

159 and 2090).

160 The resistance layer in our study of butterflies is equal to the sum of the habitat suitability

161 model and Global Human Footprint data (Venter et al. 2018). The Global Human Footprint is

162 a measure of human impact (Venter et al. 2018), where cells with high impact are associated 
163 with high resistance, likely to be a function of dispersal limitation rather than habitat

164 suitability, as urban and agricultural areas can reduce the ability of butterflies to move across

165 landscapes and infrastructure such as roads results in significant mortality of butterflies

166 (Chowdhury et al. 2021b). The predicted habitat-suitability data ranges from 0.0 to 1.0 (low

167 to high resistance), while the Global Human Footprint data ranges from 0.0 to 100.0 (high to

168 low). To match the scale and direction of these two data sets, we transformed the habitat

169 suitability data by subtracting the data from 1 and multiplying it by 100 . The transformed

170 habitat suitability data was added to the Global Human Footprint data and then rounded up to

171 the nearest integer, because Circuitscape does not accept non-integer values. Due to the

172 unavailability of future Global Human Footprint data, we were forced to assume that this data

173 is constant under present conditions and future scenarios. The final resistance layer scales

174 from 0 to 200 (lowest to highest possible resistance). Resistance layers were created for each

175 species under present climate conditions and future climate scenarios (for 2050 and 2090).

176 We predicted the functional connectivity for each species under present conditions and then

177 calculated their goodness of fit (AUC) to assess model accuracy (Jackson et al. 2016). We

178 also calculated the mean cumulative current (with standard error) of the connectivity models.

179 If a pixel facilitates connectivity, then the presence points should on average have higher

180 values than pseudo-absences (Grafius et al. 2017; Rodrigues et al. 2021). We then predicted

181 the functional connectivity for each species under future scenarios (for 2050 and 2090). And

182 assessed the difference in functional connectivity between present conditions and future

183 scenarios (i.e., future minus present functional connectivity model) as well. 
186 The habitat suitability models for all 59 Australian butterfly species with sufficient data

187 achieved high goodness of fit for both AUC and TSS scores. The highest and lowest AUC

188 scores were 0.99 and 0.94 respectively, while the highest and lowest TSS scores were 0.92

189 and 0.65 respectively (Supplemental Table A1). The connectivity models also achieved high-

190 to-moderate goodness of fit, with AUC scores ranging between 0.94 and 0.68

191 (Supplementary Table A1). The mean cumulative current of the presence points was higher

192 than that of the pseudo-absences for functional connectivity models of all species

193 (Supplementary Fig. A1-2).

194 The circuit-theory results (a proxy for functional connectivity) of all the families except for

195 Papilionidae predicted similar future trends, with mean cumulative current expected to

196 decrease through to 2090 (Fig. 1). However, the results for individual species provided a

197 more nuanced perspective than looking at families and exhibited considerably more variation.

198 For example, Dispar compacta (Hesperiidae) has a higher mean cumulative current than

199 Hypolycaena phorbas (Lycaenidae) with current predicted to decrease for the former and

200 increase for the latter (Fig. 2b, d), whereas for Acraea andromacha (Nymphalidae) and

201 Graphium choredon (Papilionidae), future scenarios show similar results to present-day

202 conditions (Fig. 2a, c). 


\section{a. Hesperiidae}

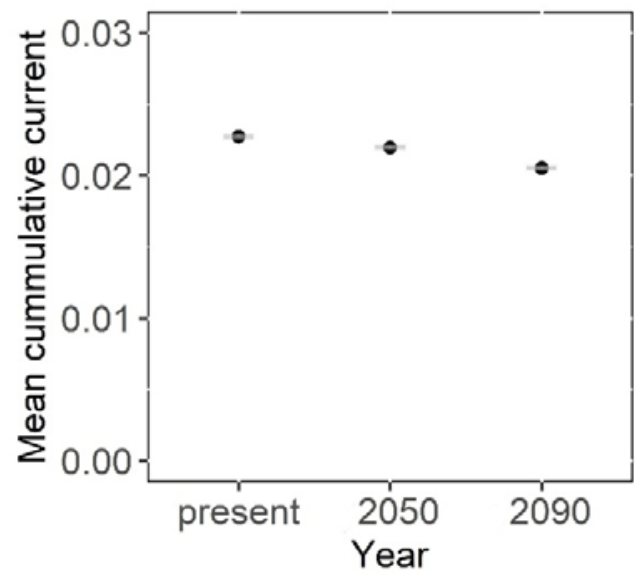

c. Nymphalidae

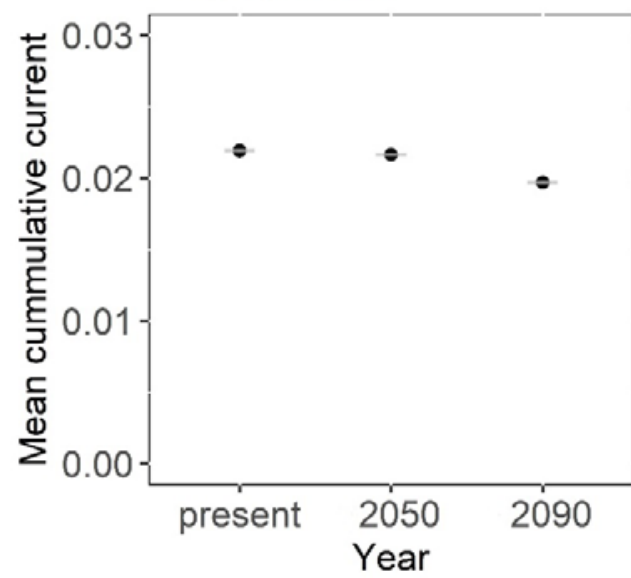

b. Lycaenidae

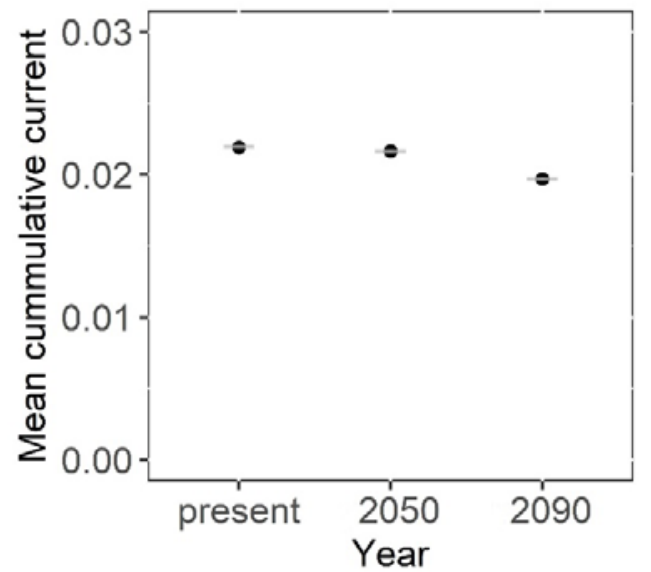

d. Papilionidae

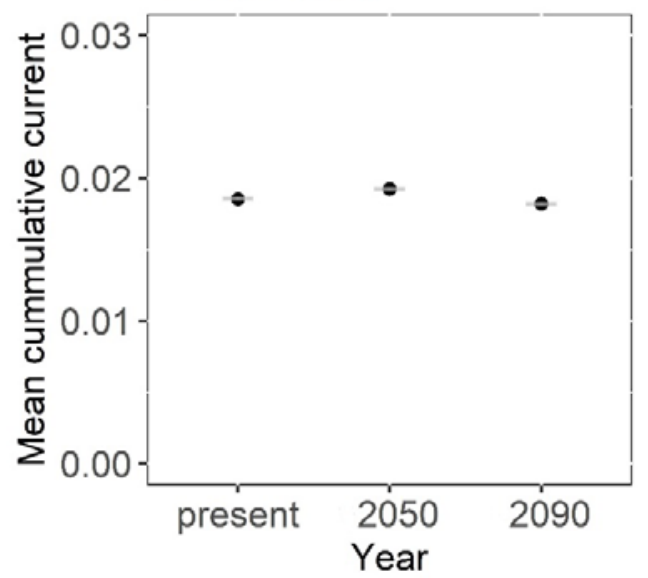

204 Fig 1. Mean cumulative current with standard error of the families (a) Hesperiidae (b)

205 Lycaenidae, (c) Nymphalidae, and (d) Papilionidae under present conditions and future

206 scenarios of climate change (for the year 2050 and 2090). 
a. Acraea andromacha

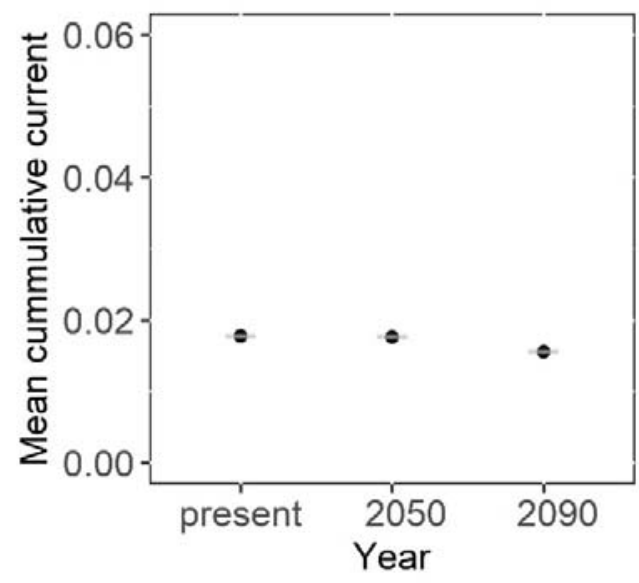

c. Graphium choredon

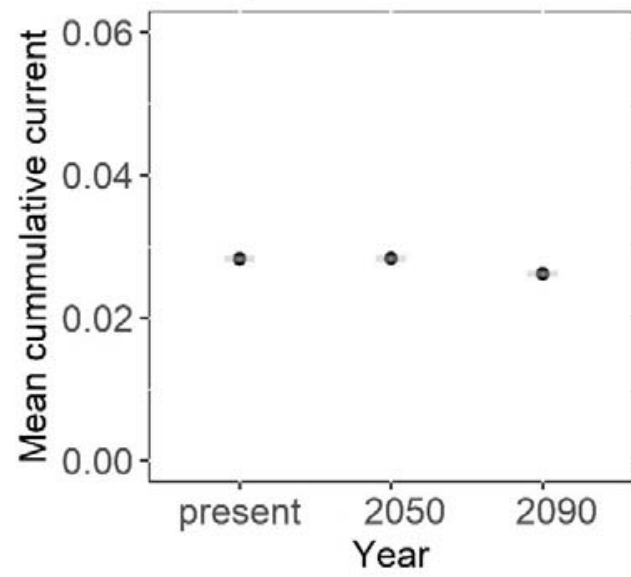

b. Dispar compacta

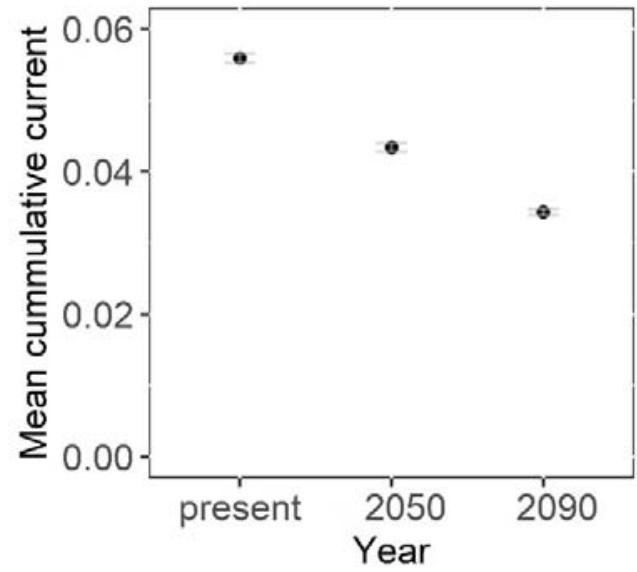

d. Hypolycaena phorbas

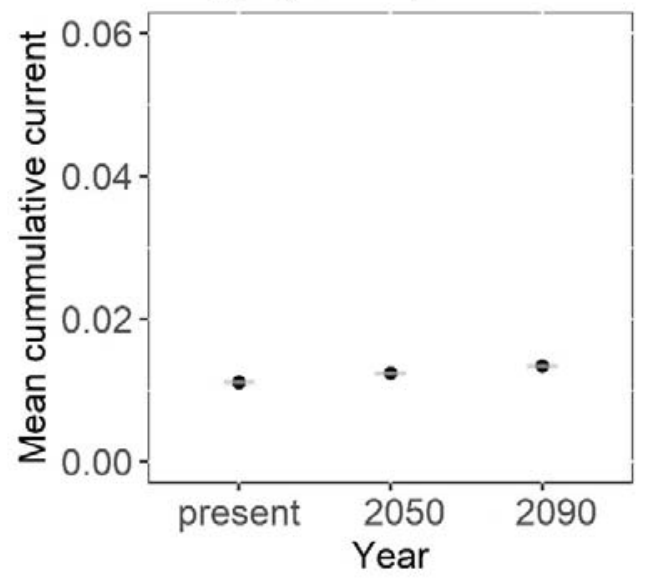

208 Fig 2. Mean cumulative current with standard error of the species (a) Acraea andromacha (b)

209 Dispar compacta, (c) Graphium choredon, and (d) Hypolycaena phorbas under present

210 conditions and future scenarios (the year 2050 and 2090).

212 Under present conditions, functional connectivity is modelled to vary between species and

213 regionally, including those with similar geographical ranges. For example, Catochrysops

214 panormus has higher connectivity along the northern part of Australia than Graphium

215 eurypylus, Papilio fuscus, and Ypthima arctous (Fig. 3), while Graphium eurypylus and

216 Ypthima arctous have higher connectivity along the eastern coast than the other species (Fig

217 3), although those species are found across a similar geographic range. 
a. Catochrysops panormus

b. Graphium eurypylus
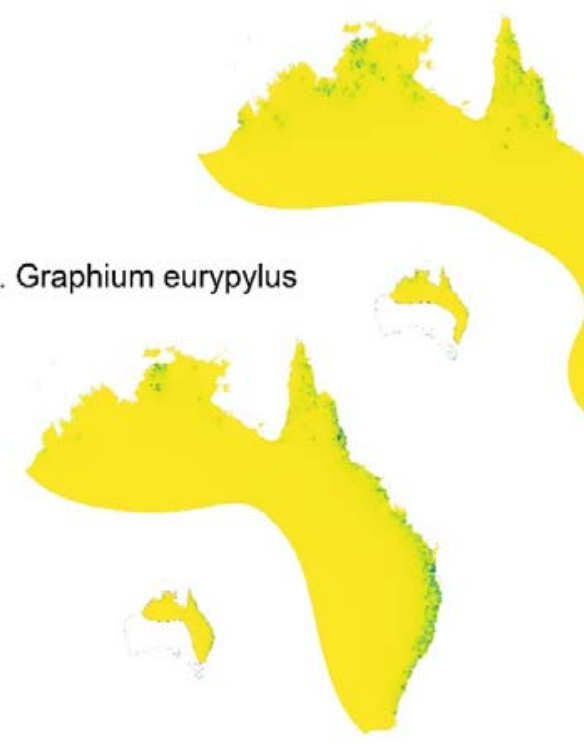

c. Papilio fuscus

d. Ypthima arctous

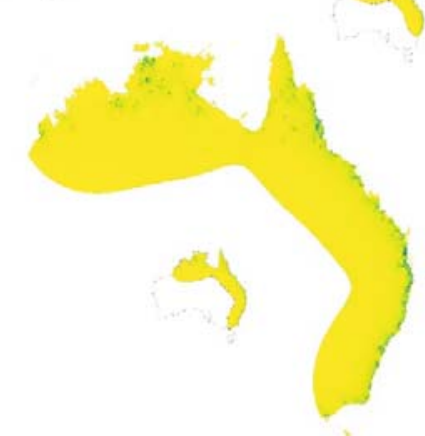

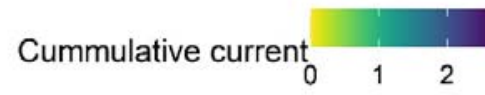

219 Fig 3. Functional connectivity of the species (a) Catochrysops panormus (b) Graphium

220 eurypylus, (c) Papilio fuscus, and (d) Ypthima arctous under present-day conditions.

222 Most species (43 out of 59) showed consistent, ongoing declines in functional connectivity

223 between the present and 2090 (Fig. 4). For Arhopala eupolis, Candalides erinus, Cephrenes

224 augiades, Jamides phaseli, Nacaduba biocellata, Oreixenica ptunarra, Papilio fuscus,

225 Trapezites symmomus, and Vanessa kershawi (9 out of the 59 species) the percentage of

226 change between future scenarios 2050 and 2090 are similar (Fig 4). While for Charaxes

227 sempronius, Cressida cressida, Famegana alsulus, Hypolycaena phorbas, Junonia hedonia,

228 Pelopidas lyelli, and Zizeeria karsandra (7 out of the 59 species) the percentage of positive

229 changes is higher in the year 2090 than in 2050 (Fig 4).

230 Although the percentage of change between future scenarios 2050 and 2090 are similar, for

231 the Oreixenica ptunarra (Fig. 4) functional connectivity is still predicted to decrease, 
bioRxiv preprint doi: https://doi.org/10.1101/2022.02.07.479372; this version posted February 10,2022. The copyright holder for this preprint (which was not certified by peer review) is the author/funder, who has granted bioRxiv a license to display the preprint in perpetuity. It is made available under aCC-BY-NC-ND 4.0 International license.

232 particularly along the north-west and eastern parts of its range (Fig. 5a-c). And while the

233 percentage of positive changes is higher in the year 2090 than 2050 for Pelopidas lyelli and

234 Famegana alsulus (Fig 4) functional connectivity is predicted to increase along the southern

235 part of the range for Pelopidas lyelli (Fig. 5d-f) and along the north-eastern part of the range

236 for Famegana alsulus (Fig. 5g-i)

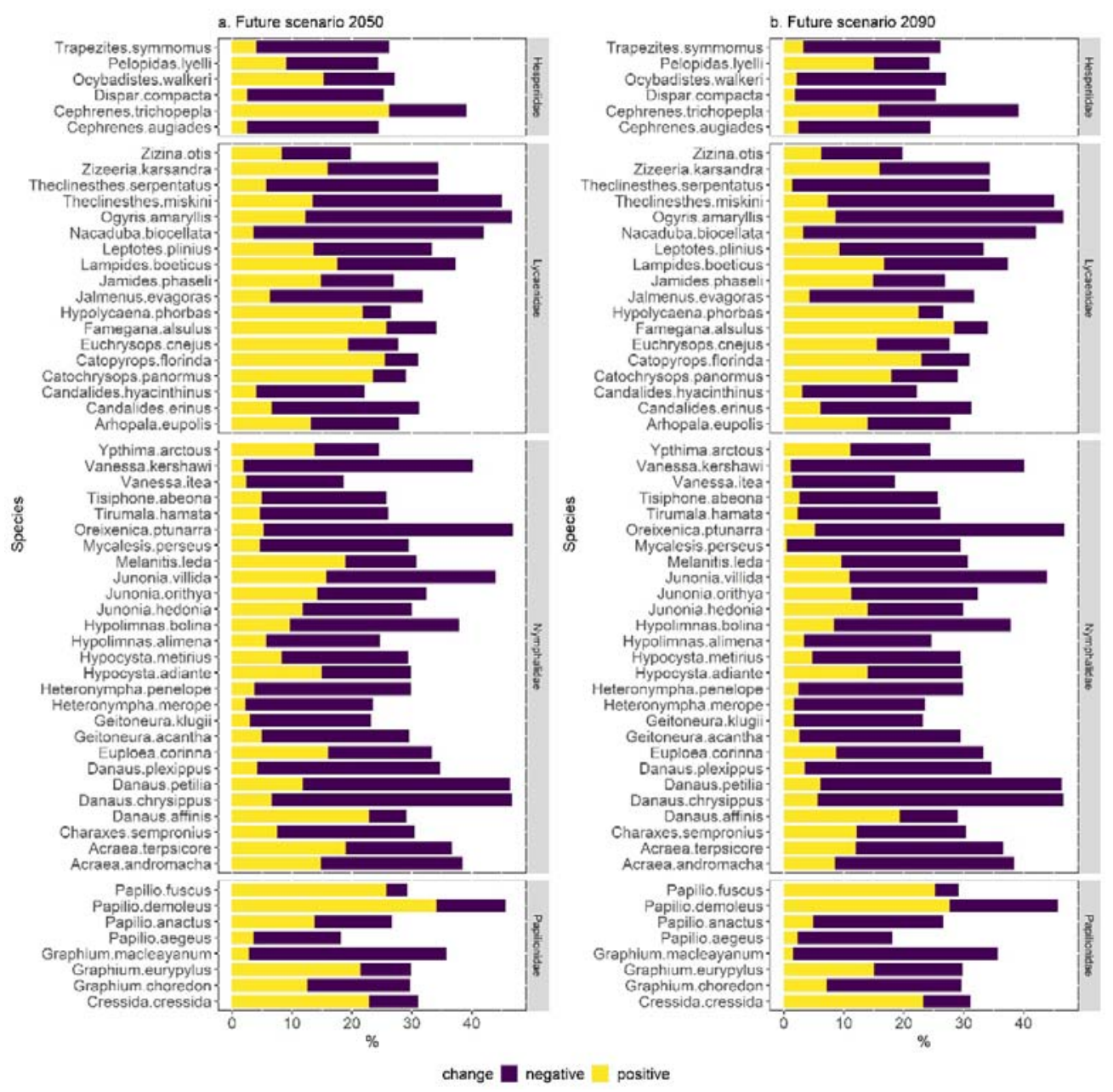

238 Fig 4. Percentage of negative and positive changes in functional connectivity for each

239 Australian butterfly species, grouped by family, under future scenarios (a) 2050 and (b) 2090. 


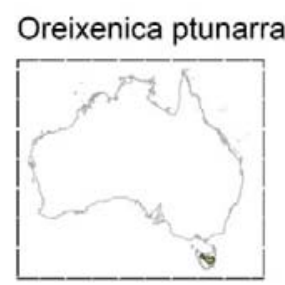

a. Present condition

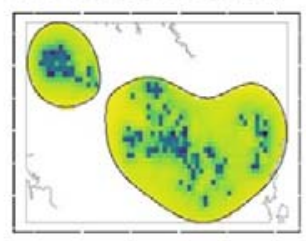

b. Future scenario 2050

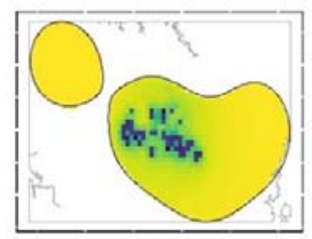

c. Future scenario 2090

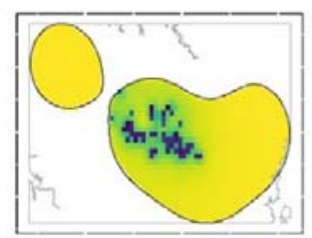

Pelopidas Iyelli

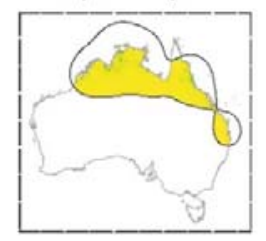

d. Present condition

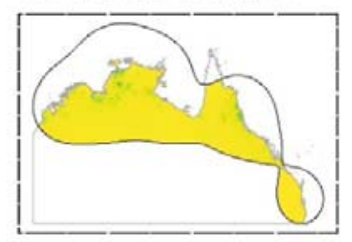

e. Future scenario 2050

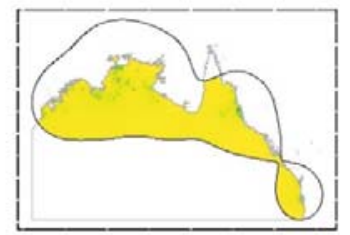

f. Future scenario 2090

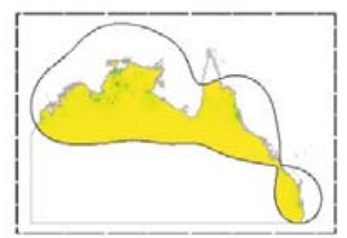

Cummulative current ${ }_{0} \quad 2$
Famegana alsulus

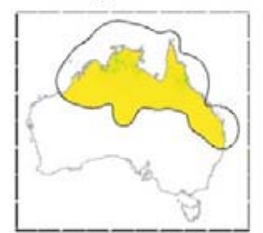

g. Present condition

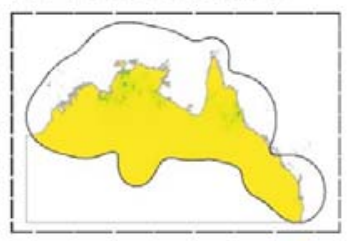

h. Future scenario 2050

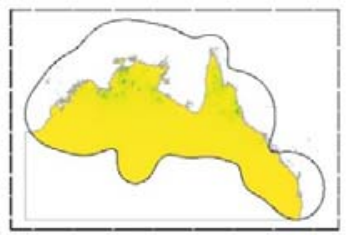

i. Future scenario 2090

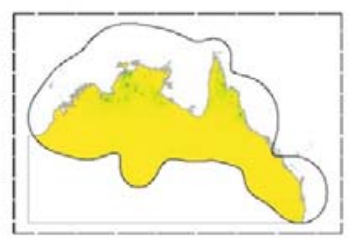

241 Fig 5. Functional connectivity of the species (a-c) Oreixenica ptunarra, (d-f) Pelopidas lyelli,

242 and (g-i) Famegana alsulus under present conditions and future scenarios (for 2050 and

243 2090).

245 Changes in functional connectivity were predicted to occur both along the periphery of a

246 species' geographical range and within the core. For example, functional connectivity was

247 predicted to be lost along the north-east range for Geitoneura klugii and Heteronympha

248 Penelope (Fig. 6) as well as within the core of their ranges. In some cases, functional

249 connectivity is also predicted to increase along the edges, for example, there is an increase

250 along the south-west of the island of Tasmania for the Geitoneura klugii (Fig. 6a, b). 


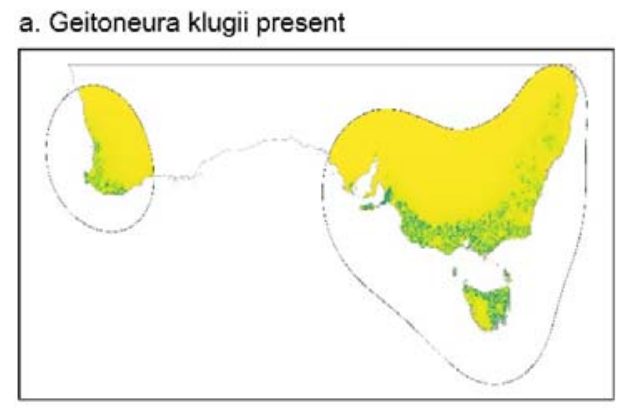

c. Heteronympha penelope present

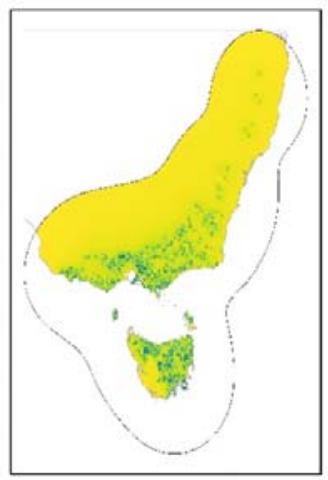

b. Geitoneura klugii 2090

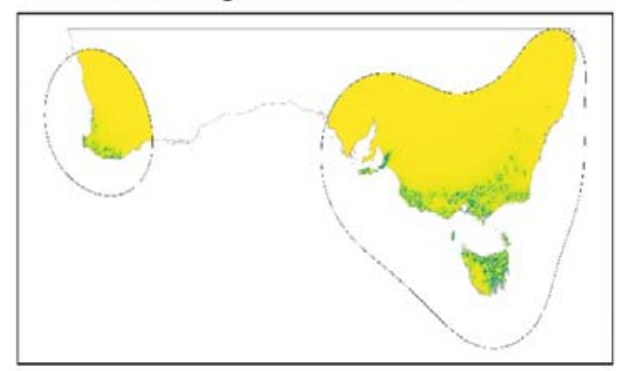

d. Heteronympha penelope 2090

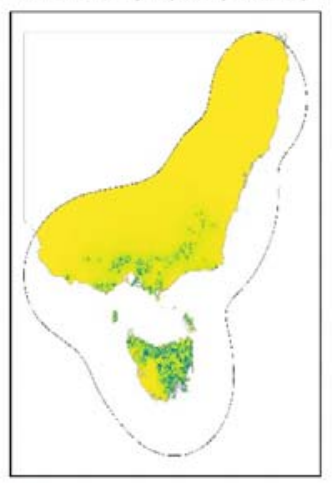

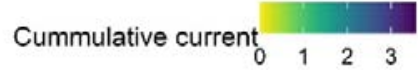

252 Fig 6. Functional connectivity of Geitoneura klugii (a-b) and Heteronympha penelope (c-d)

253 under present conditions and future scenarios.

\section{Discussion}

256 Butterflies are an ecologically important and conspicuous pollinating taxon that is threatened

257 by habitat loss/fragmentation and climate change (Miao et al. 2020; Warren et al. 2021).

258 These threats can be mitigated by conserving and promoting functional connectivity, making

259 it crucial that ecologists seek to identify such areas. Overall, our analysis predicts that

260 functional connectivity will show an overall decrease, with most butterfly species

261 experiencing a higher percentage of negative changes than positive; a trend that worsens over

262 time. Below we highlight how modelling can assist in the decision making of where

263 ecological corridors and stepping-stone habitats should be prioritised. 
264 Under present conditions, the mean cumulative current is overall predicted to be higher along

265 areas with core habitats or focal nodes (i.e., areas with high habitat suitability); a finding

266 common to studies of other taxa such as African elephants (Roever et al. 2013), birds

267 (Grafius et al. 2017), and ungulates (Malakoutikhah et al. 2020). The differences and

268 similarities in functional connectivity between butterfly species with similar (estimated)

269 ranges can be attributed, in large part, to their habitat preferences. For example, C. panormus

270 (functional connectivity predicted to decrease; Fig 4) occur in open eucalyptus forest and

271 savannah woodland, whereas G. eurypylus (functional connectivity predicted to decrease; Fig

272 4) occur in monsoon forest, rainforest, and even urban gardens (Braby 2000). As another

273 relevant contrast of species with similar-sized geographic ranges but different responses are,

274 P. fuscus, (functional connectivity predicted to remain similar between 2050 and 2090; Fig 4)

275 being found in coastal and subcoastal lowlands rainforest and monsoon forest, compared to $Y$.

276 arctous (functional connectivity predicted to decrease; Fig 4), which prefers coastal and

277 subcoastal woodlands and open forest (Braby 2000).

278 Overall, we predicted the functional connectivity of most butterfly species in Australia to

279 decrease over the coming decades, albeit with a few exceptions. Our predictions are similar to

280 studies that predicted several non-butterfly taxa such as the Sichuan snub $\square$ nosed monkey

281 (Zhang et al. 2019b), ungulates (Malakoutikhah et al. 2020; Liang et al. 2021), and the

282 Himalayan brown bear (Mukherjee et al. 2021) to experience a future decrease in functional

283 connectivity due to climate change in different parts of the world. To our knowledge, this is

284 the first attempt to predict the combined impacts of land-use, land-cover, and climate change

285 on the functional connectivity of butterflies.

286 The mean cumulative circuit-theory 'current' is overall predicted to be highest along areas

287 with the best habitat suitability for a given species. The predicted decrease in functional

288 connectivity for most species is expected because climate change is predicted to change the 
289 geographic distributions of butterflies (Adhikari et al. 2020; Minachilis et al. 2021). Overall,

290 most of the changes are predicted along the edges of a species range, because populations

291 along boundaries are generally inhabiting the limits of their physiological tolerances

292 compared to those at the core, leaving them more vulnerable to climate change (Parmesan et

293 al. 2000). These changes could also be due to land-use and land-cover change which is

294 observed (Zhang et al. 2019a; Wang et al. 2020) and predicted (Li et al. 2017) to result in loss

295 of forest areas which could have negative impacts on species depending on such habitats.

296 Overall land-use and land-cover change have a negative impact on biodiversity in Australia

297 including on butterflies (Thackway 2018; Davidson et al. 2021; Kutt et al. 2021).

298 Given the continental scale of the study area and the number of species assessed, there were a

299 few limitations to the study. Spatial scale can influence functional connectivity models

300 (Laliberté and St-Laurent 2020) and while 1-km spatial resolution predictors are available,

301 the extent of the study area and the high computational requirements forced us to use a

302 coarser resolution of $5 \mathrm{~km}$. The accuracy of the habitat suitability models can be influenced

303 by several factors, including the temporal equilibrium (or lack thereof) between data points

304 (species observations) and the geophysical and landscape predictors, as well as the interaction

305 between the spatial scale of the predictors and attributes of the species (Dormann 2007).

306 Validating functional connectivity models is a challenging process (Laliberté and St-Laurent

307 2020), with suggested methods including field observations by scientists or automated field

308 recorders (e.g., camera traps, acoustic recorders), along with accurate GPS data (Grafius et al.

309 2017; Finch et al. 2020; Laliberté and St-Laurent 2020). However, in this study, we used

310 citizen science data to build and validate the models, because of the scale of the study area

311 and the number of species studied, which has the advantage of volume, but the constraint of a

312 lower-level of precision and quality control. 


\section{5. Conclusion}

315 Butterflies are an important pollinating group, but the functional connectivity for several

316 species are predicted to decrease across Australia in the coming decade due to the combined

317 impacts of land-use, land-cover and climate change. Conservation efforts are being made to

318 improve ecological corridors and stepping-stone habitat-restoration programs to promote

319 functional connectivity, in some cases these efforts include invertebrates such as bees (e.g.,

320 Miranda et al. 2021) in other cases the focus is only on vertebrate taxa (e.g., Jones et al.

321 2021). We advocate conservation efforts should include butterflies and other pollinating taxa

322 as well. The availability of our results as a spatial dataset, along with analogous findings from

323 other taxa, will assist in identifying priority conservation areas. Future studies on butterflies

324 should consider (1) collecting dispersal data, to build better connectivity models given that

325 radio telemetry for butterflies is now becoming a logistically viable option (Wang et al.

326 2019), (2) improving the resistance layer by including spatial data that contains food plants

327 that caterpillars feed upon and butterflies pollinate (Kass et al. 2020), and (3) focussing on

328 species most threatened (Geyle et al. 2021), to develop more targeted, species-specific

329 conservation efforts.

\section{$331 \quad$ References}

332 Adhikari P, Jeon J-Y, Kim HW, Oh H-S, Adhikari P, Seo C (2020) Northward Range

333 Expansion of Southern Butterflies According to Climate Change in South Korea. Journal of

334 Climate 11(6-1):643-656 http://dx.doi.org/10.15531/KSCCR.2020.11.6.643 
335 Aiello-Lammens ME, Boria RA, Radosavljevic A, Vilela B, Anderson RP (2015) spThin: an

$336 \mathrm{R}$ package for spatial thinning of species occurrence records for use in ecological niche

337 models. Ecography 38(5):541-545 https://doi.org/10.1111/ecog.01132

338 Allouche O, Tsoar A, Kadmon R (2006) Assessing the accuracy of species distribution

339 models: prevalence, kappa and the true skill statistic (TSS). Journal of Applied Ecology

340 43(6):1223-1232 https://doi.org/10.1111/j.1365-2664.2006.01214.x

341 Amin RJ, Buettel JC, Fielding MW, Vaughan PM, Brook BW (2021) Hot, unpredictable

342 weather interacts with land use to restrict the distribution of the Yellow-tailed Black-

343 Cockatoo. Emu - Austral Ornithology:1-10 https://doi.org/10.1080/01584197.2021.1952083

344 Anantharaman R, Hall K, Shah V, Edelman A (2020) Circuitscape in Julia: High

345 Performance Connectivity Modelling to Support Conservation Decisions. Proceedings of the

346 JuliaCon Conferences 1:1 https://doi.org/10.21105/jcon.00058

347 Ashrafzadeh MR, Naghipour AA, Haidarian M, Kusza S, Pilliod DS (2019) Effects of

348 climate change on habitat and connectivity for populations of a vulnerable, endemic

349 salamander in Iran. Global Ecology and Conservation 19:e00637

350 https://doi.org/10.1016/j.gecco.2019.e00637

351 Bonnin N, Stewart FA, Wich SA, Pintea L, Jantz SM, Dickson R, Bellis J, Chitayat A,

352 Ingram R, Moore RJ (2020) Modelling landscape connectivity change for chimpanzee

353 conservation in Tanzania. Biological Conservation 252:108816

354 https://doi.org/10.1016/j.biocon.2020.108816

355 Braby MF (2000) Butterflies of Australia: their identification, biology and distribution.

356 CSIRO publishing 
357 Breiman L (2001) Random forests. Machine learning 45(1):5-32

358 https://doi.org/10.1023/A:1010933404324

359 Briscoe NJ, Kearney MR, Taylor CA, Wintle BA (2016) Unpacking the mechanisms

360 captured by a correlative species distribution model to improve predictions of climate refugia.

361 Global Change Biology 22(7):2425-2439 https://doi.org/10.1111/gcb.13280

362 Calenge C (2006) The package "adehabitat" for the R software: a tool for the analysis of

363 space and habitat use by animals. Ecological Modelling 197(3-4):516-519

364 https://doi.org/10.1016/j.ecolmodel.2006.03.017

365 Chen N (2017) Assessing Landscape Effects on Genetics and Dispersal of the Rocky

366 Mountain Apollo Butterfly Parnassius smintheus using a Resistance Mapping Approach. The

367 University of Western Ontario https://ir.lib.uwo.ca/etd/5058

368 Cheng W, Bonebrake TC (2017) Conservation effectiveness of protected areas for Hong

369 Kong butterflies declines under climate change. Journal of Insect Conservation 21(4):599-

$370 \quad 606$ https://doi.org/10.1007/s10841-017-9998-7

371 Chowdhury S, Alam S, Chowdhury SU, Rokonuzzaman M, Shahriar SA, Shome AR, Fuller

372 RA (2021a) Butterflies are weakly protected in a mega-populated country, Bangladesh.

373 Global Ecology and Conservation 26:e01484 https://doi.org/10.1016/j.gecco.2021.e01484

374 Chowdhury S, Fuller RA, Dingle H, Chapman JW, Zalucki MP (2021b) Migration in

375 butterflies: a global overview. Biological Reviewshttps://doi.org/10.1111/brv.12714

376 Convention on Biological Diversity (2022) Aichi Biodiversity Target. Accessed 04 February

3772022 https://www.cbd.int/aichi-targets/ 
378 Correa Ayram CA, Mendoza ME, Etter A, Salicrup DRP (2016) Habitat connectivity in

379 biodiversity conservation: A review of recent studies and applications. Progress in Physical

380 Geography 40(1):7-37 https://doi.org/10.1177/0309133315598713

381 Costanza JK, Terando AJ (2019) Landscape connectivity planning for adaptation to future

382 climate and land-use change. Current Landscape Ecology Reports 4(1):1-13

383 https://doi.org/10.1007/s40823-019-0035-2

384 Cover TM, Hart PE (1967) Nearest Neighbor Pattern Classification. IEEE Transactions on

385 Information Theory 13(1):21-27 https://doi.org/10.1109/Tit.1967.1053964

386 Davidson NJ, Bailey TG, Burgess S (2021) Restoring the Midlands of Tasmania: an

387 introduction. Ecological Management \& Restoration 22:3-10

388 https://doi.org/10.1111/emr.12522

389 Dickson BG, Albano CM, Anantharaman R, Beier P, Fargione J, Graves TA, Gray ME, Hall

390 KR, Lawler JJ, Leonard PB (2019) Circuit $\square$ theory applications to connectivity science and

391 conservation. Conservation Biology 33(2):239-249 https://doi.org/10.1111/cobi.13230

392 Dormann CF (2007) Promising the future? Global change projections of species distributions.

393 Basic and Applied Ecology 8(5):387-397 https://doi.org/10.1016/j.baae.2006.11.001

394 Dormann CF, Calabrese JM, Guillera $\square$ Arroita G, Matechou E, Bahn V, Bartoń K, Beale CM,

395 Ciuti S, Elith J, Gerstner K (2018) Model averaging in ecology: a review of Bayesian,

396 information $\square$ theoretic, and tactical approaches for predictive inference. Ecological

397 Monographs 88(4):485-504 https://doi.org/10.1002/ecm.1309

398 Dormann CF, Elith J, Bacher S, Buchmann C, Carl G, Carré G, Marquéz JRG, Gruber B,

399 Lafourcade B, Leitao PJ (2013) Collinearity: a review of methods to deal with it and a 
400 simulation study evaluating their performance. Ecography 36(1):27-46

401 https://doi.org/10.1111/j.1600-0587.2012.07348.x

402 Fick SE, Hijmans RJ (2017) WorldClim 2: new $1 \square \mathrm{km}$ spatial resolution climate surfaces for

403 global land areas. International Journal of Climatology 37(12):4302-4315

404 https://doi.org/10.1002/joc.5086

405 Filz KJ, Engler JO, Stoffels J, Weitzel M, Schmitt T (2013) Missing the target? A critical

406 view on butterfly conservation efforts on calcareous grasslands in south-western Germany.

407 Biodiversity and Conservation 22(10):2223-2241 https://doi.org/10.1007/s10531-012-0413-0

408 Finch D, Corbacho DP, Schofield H, Davison S, Wright PG, Broughton RK, Mathews F

409 (2020) Modelling the functional connectivity of landscapes for greater horseshoe bats

410 Rhinolophus ferrumequinum at a local scale. Landscape Ecology 35(3):577-589

411 https://doi.org/10.1007/s10980-019-00953-1

412 Geyle HM, Braby MF, Andren M, Beaver EP, Bell P, Byrne C, Castles M, Douglas F, Glatz

413 RV, Haywood B (2021) Butterflies on the brink: identifying the Australian butterflies

414 (Lepidoptera) most at risk of extinction. Austral Entomology

415 https://doi.org/10.1111/aen.12525

416 Grafius DR, Corstanje R, Siriwardena GM, Plummer KE, Harris JA (2017) A bird's eye

417 view: using circuit theory to study urban landscape connectivity for birds. Landscape

418 Ecology 32(9):1771-1787 https://doi.org/10.1007/s10980-017-0548-1

419 Hastie T, Tibshirani R, Buja A (1994) Flexible discriminant analysis by optimal scoring.

420 Journal of the American Statistical Association 89(428):1255-1270

421 https://doi.org/10.1080/01621459.1994.10476866 
422 Hijmans RJ (2020) raster: Geographic Data Analysis and Modeling. 3.4-5

423 IPCC (2021) Climate Change 2021: The Physical Science Basis. Contribution of Working

424 Group I to the Sixth Assessment Report of the Intergovernmental Panel on Climate Change

425 Masson-Delmotte V., P. Zhai, A. Pirani, S.L. Connors, C. Péan, S. Berger, N. Caud, Y. Chen,

426 L. Goldfarb, M.I. Gomis, M. Huang, K. Leitzell, E. Lonnoy, J.B.R. Matthews, T.K.

427 Maycock, T. Waterfield, O. Yelekçi, R. Yu, and B. Zhou. Cambridge University Press. In

428 Press.

429 Jackson CR, Marnewick K, Lindsey PA, Røskaft E, Robertson MP (2016) Evaluating habitat

430 connectivity methodologies: a case study with endangered African wild dogs in South Africa.

431 Landscape Ecology 31(7):1433-1447 https://doi.org/10.1007/s10980-016-0342-5

432 Jones ME, Bain GC, Hamer RP, Proft KM, Gardiner RZ, Dixon KJ, Kittipalawattanapol K,

433 Zepeda de Alba AL, Ranyard CE, Munks SA (2021) Research supporting restoration aiming

434 to make a fragmented landscape 'functional' for native wildlife. Ecological Management \&

435 Restoration 22:65-74 https://doi.org/10.1111/emr.12504

436 Kass JM, Anderson RP, Espinosa $\square$ Lucas A, Juárez $\square$ Jaimes V, Martínez $\square$ Salas E, Botello F,

437 Tavera G, Flores $\square$ Martínez JJ, Sánchez $\square$ Cordero V (2020) Biotic predictors with

438 phenological information improve range estimates for migrating monarch butterflies in

439 Mexico. Ecography 43(3):341-352 https://doi.org/10.1111/ecog.04886

440 Kirk H, Threlfall C, Soanes K, Ramalho C, Parris K, Amati M, Bekessy S, Mata L (2018)

441 Improving connectivity for biodiversity across the City of Melbourne: A framework for

442 evaluating and planning management actions. Report prepared for the City of Melbourne

443 Urban Sustainability Branch.

444 Kuhn M (2021) caret: Classification and Regression Training. 6.0-86 
445 Kutt AS, Dickson CR, Quarmby J, Kingdom D, Hamer RP (2021) Evaluating predictors of

446 Ptunarra Brown Butterfly Oreixenica ptunarra abundance on a conservation reserve to refine

447 future monitoring. Ecological Management \& Restoration https://doi.org/10.1111/emr.12544

448 Laliberté J, St-Laurent M-H (2020) Validation of functional connectivity modeling: The

449 Achilles' heel of landscape connectivity mapping. Landscape and Urban Planning

$450 \quad$ 202:103878 https://doi.org/10.1016/j.landurbplan.2020.103878

451 Li X, Chen G, Liu X, Liang X, Wang S, Chen Y, Pei F, Xu X (2017) A new global land-use

452 and land-cover change product at a 1-km resolution for 2010 to 2100 based on human-

453 environment interactions. Annals of the American Association of Geographers 107(5):1040-

$454 \quad 1059$ https://doi.org/10.1080/24694452.2017.1303357

455 Liang J, Ding Z, Jiang Z, Yang X, Xiao R, Singh PB, Hu Y, Guo K, Zhang Z, Hu H (2021)

456 Climate change, habitat connectivity, and conservation gaps: a case study of four ungulate

457 species endemic to the Tibetan Plateau. Landscape Ecology 36(4):1071-1087

458 https://doi.org/10.1007/s10980-021-01202-0

459 Littlefield CE, Krosby M, Michalak JL, Lawler JJ (2019) Connectivity for species on the

460 move: supporting climate $\square$ driven range shifts. Frontiers in Ecology and the Environment

461 17(5):270-278 https://doi.org/10.1002/fee.2043

462 Malakoutikhah S, Fakheran S, Hemami MR, Tarkesh M, Senn J (2020) Assessing future

463 distribution, suitability of corridors and efficiency of protected areas to conserve vulnerable

464 ungulates under climate change. Diversity and Distributions 26(10):1383-1396

465 https://doi.org/10.1111/ddi.13117 
466 McRae BH, Dickson BG, Keitt TH, Shah VB (2008) Using circuit theory to model

467 connectivity in ecology, evolution, and conservation. Ecology 89(10):2712-2724

468 https://doi.org/10.1890/07-1861.1

469 Miao BG, Peng YQ, Yang DR, Kubota Y, Economo EP, Liu C (2020) Climate and land $\square$ use

470 interactively shape butterfly diversity in tropical rainforest and savanna ecosystems of

471 southwestern China. Insect science 28(4):1109-1120 https://doi.org/10.1111/1744-

$472 \quad \underline{7917.12824}$

473 Minachilis K, Kougioumoutzis K, Petanidou T (2021) Climate change effects on multi-taxa

474 pollinator diversity and distribution along the elevation gradient of Mount Olympus, Greece.

475 Ecological Indicators 132:108335 https://doi.org/10.1016/j.ecolind.2021.108335

476 Miranda LdS, Awade M, Jaffé R, Costa WF, Trevelin LC, Borges RC, de Brito RM, Tambosi

477 LR, Giannini TC (2021) Combining connectivity and species distribution modeling to define

478 conservation and restoration priorities for multiple species: a case study in the Eastern

479 Amazon. Biological Conservation 257:109148 https://doi.org/10.1016/j.biocon.2021.109148

480 Mitchell MG, Bennett EM, Gonzalez A (2013) Linking landscape connectivity and

481 ecosystem service provision: current knowledge and research gaps. Ecosystems 16(5):894-

482908 https://doi.org/10.1007/s10021-013-9647-2

483 Morán $\square$ Ordóñez A, Briscoe NJ, Wintle BA (2018) Modelling species responses to extreme

484 weather provides new insights into constraints on range and likely climate change impacts for

485 Australian mammals. Ecography 41(2):308-320 https://doi.org/10.1111/ecog.02850

486 Mukherjee T, Sharma LK, Kumar V, Sharief A, Dutta R, Kumar M, Joshi BD, Thakur M,

487 Venkatraman C, Chandra K (2021) Adaptive spatial planning of protected area network for 
488 conserving the Himalayan brown bear. Science of the Total Environment 754:142416

489 https://doi.org/10.1016/j.scitotenv.2020.142416

490 Ofori BY, Stow AJ, Baumgartner JB, Beaumont LJ (2017) Combining dispersal, landscape

491 connectivity and habitat suitability to assess climate-induced changes in the distribution of

492 Cunningham's skink, Egernia cunninghami. PLOS One 12(9):e0184193

493 https://doi.org/10.1371/journal.pone.0184193

494 Parmesan C, Root TL, Willig MR (2000) Impacts of extreme weather and climate on

495 terrestrial biota. Bulletin of the American Meteorological Society 81(3):443-450

496 https://doi.org/10.1175/1520-0477(2000)081<0443:IOEWAC>2.3.CO;2

497 Potts SG, Ngo HT, Biesmeijer JC, Breeze TD, Dicks LV, Garibaldi LA, Hill R, Settele J,

498 Vanbergen A (2016) The assessment report of the Intergovernmental Science-Policy Platform

499 on Biodiversity and Ecosystem Services on pollinators, pollination and food production.

500 Bonn, Germany, Secretariat of the Intergovernmental Science-Policy Platform on

501 Biodiversity and Ecosystem Services

502 Ren J, Lee SD, Chen X, Kao B, Cheng R, Cheung D Naive bayes classification of uncertain

503 data. In: 2009 Ninth IEEE International Conference on Data Mining, 2009. IEEE, p. 944-949

504 Rodrigues RG, Srivathsa A, Vasudev D (2021) Dog in the matrix: Envisioning countrywide

505 connectivity conservation for an endangered carnivore. Journal of Applied Ecology

506 https://doi.org/10.1111/1365-2664.14048

507 Roever CL, Van Aarde RJ, Leggett K (2013) Functional connectivity within conservation

508 networks: Delineating corridors for African elephants. Biological Conservation 157:128-135

509 https://doi.org/10.1016/j.biocon.2012.06.025 
510 Rudnick D, Ryan SJ, Beier P, Cushman SA, Dieffenbach F, Epps C, Gerber LR, Hartter JN,

511 Jenness JS, Kintsch J (2012) The role of landscape connectivity in planning and

512 implementing conservation and restoration priorities. Issues in Ecology. Report No. 16,

513 Ecological Society of America. Washington, DC.

514 Samways MJ, Barton PS, Birkhofer K, Chichorro F, Deacon C, Fartmann T, Fukushima CS,

515 Gaigher R, Habel JC, Hallmann CA (2020) Solutions for humanity on how to conserve

516 insects. Biological Conservation 242:108427 https://doi.org/10.1016/j.biocon.2020.108427

517 Sands DP (2018) Important issues facing insect conservation in Australia: now and into the

518 future. Austral Entomology 57(2):150-172 https://doi.org/10.1111/aen.12342

519 Sazli MH (2006) A brief review of feed-forward neural networks. Communications Faculty

520 of Sciences University of Ankara Series A2-A3 Physical Sciences and Engineering 50(01)

521 https://doi.org/10.1501/commua1-2 0000000026

522 Stewart FE, Darlington S, Volpe JP, McAdie M, Fisher JT (2019) Corridors best facilitate

523 functional connectivity across a protected area network. Scientific Reports 9(1):1-9

524 https://doi.org/10.1038/s41598-019-47067-X

525 Thackway R (2018) Land Use in Australia: Past, Present and Future. ANU Press

526 Venter O, Sanderson EW, Magrach A, Allan JR, Beher J, Jones KR, Possingham HP,

527 Laurance WF, Wood P, Fekete BM, Levy MA, Watson JE (2018) Last of the Wild Project,

528 Version 3 (LWP-3): 2009 Human Footprint, 2018 Release https://doi.org/10.7927/H46T0JQ4

529 Wang SW, Gebru BM, Lamchin M, Kayastha RB, Lee W-K (2020) Land use and land cover

530 change detection and prediction in the Kathmandu district of Nepal using remote sensing and

531 GIS. Sustainability 12(9):3925 https://doi.org/10.3390/su12093925 
532 Wang Z, Huang Y, Pierce NE (2019) Radio telemetry helps record the dispersal patterns of

533 birdwing butterflies in mountainous habitats: Golden Birdwing (Troides aeacus) as an

534 example. Journal of Insect Conservation 23(4):729-738 https://doi.org/10.1007/s10841-019-

$535 \quad \underline{00167-5}$

536 Warren MS, Maes D, van Swaay CA, Goffart P, Van Dyck H, Bourn NA, Wynhoff I, Hoare

537 D, Ellis S (2021) The decline of butterflies in Europe: Problems, significance, and possible

538 solutions. Proceedings of the National Academy of Sciences 118(2)

539 https://doi.org/10.1073/pnas.2002551117

540 Winfree R, Bartomeus I, Cariveau DP (2011) Native Pollinators in Anthropogenic Habitats.

541 Annual Review of Ecology, Evolution, and Systematics 42:1-22

542 https://doi.org/10.1146/annurev-ecolsys-102710-145042

543 Zhang C, Zhong S, Wang X, Shen L, Liu L, Liu Y (2019a) Land use change in coastal cities

544 during the rapid urbanization period from 1990 to 2016: a case study in Ningbo City, China.

545 Sustainability 11(7):2122 https://doi.org/10.3390/su11072122

546 Zhang Y, Clauzel C, Li J, Xue Y, Zhang Y, Wu G, Giraudoux P, Li L, Li D (2019b)

547 Identifying refugia and corridors under climate change conditions for the Sichuan

548 snub $\square$ nosed monkey (Rhinopithecus roxellana) in Hubei Province, China. Ecology and

549 evolution 9(4):1680-1690 https://doi.org/10.1002/ece3.4815 